\title{
A Vision to Revive Mud Architecture, a Community Heritage Architecture in Jordan, for Low Income
}

\author{
Mohannad Tarrad \\ Department of Architecture Engineering, Faculty of Engineering, Al-Bayt University, Mafraq 130040, Jordan
}

Corresponding Author Email: ms-tarrad@aabu.edu.jo

https://doi.org/10.18280/ijdne.150218

Received: 6 November 2019

Accepted: 12 January 2020

\section{Keywords:}

mud architecture, housing policies, sustainable development, affordable housing, Jordan, mud brick

\begin{abstract}
Mud architecture is an extension of the land; it affirms the link between human beings and the earth. This technique is considered an ideal model for human adaptation to the natural environment and the sustainable exploitation of its natural resources. This realisation has led architects in different regions of the world to call for the study of heritage architecture, especially mud architecture, in their respective countries. These studies aim to develop architectural thought to converge with human instinct and encourage a shift away from modern buildings, representing the forces of globalisation that typically transform urbanisation into generic. The aim of this research was to define mud architecture and its techniques and to study how to use it in housing projects, especially in affordable housing, since previous studies have confirmed that mud houses have many possibilities to promote energy efficiency and public health through their properties of insulation and ventilation. The hypothesis of this research is that studying mud buildings is important because it shows the alignment between Jordan's architectural heritage, the concept of sustainability, and reducing the cost of construction in accordance with household income. This study focused on mud architecture in Jordan, in an attempt to promote sustainable mud architecture for use in urban construction.
\end{abstract}

\section{INTRODUCTION}

Depending on mud architecture restores the intimate relationship between human beings and their architecture, which is represented in their heritage, their instincts and interaction with their surroundings. Earth is one of oldest building materials and most ancient civilizations used it in some form. It is available, cheap and required simple technology [1]. One third of the world's population is believed to be living in buildings that are extremely varied in the construction way, but with some of similarities such as using of raw adobe bricks and compressed mud blocks [2]. Mud architecture is found in many cities and produce shelter to large numbers of persons. Mud has been considered a very essential construction material for thousands of years [3]. In Egypt, many structures are visible today, which are about 3200 years old, including storage rooms within the temple area of Rameses II near Gourna. it's clear that the technique of creating vaults and domes from earthen blocks without supports during construction was known to several cultures. for hundreds of years, Pueblo Indians in Taos, New Mexico, built houses using the sites themselves, the water from nearby streams, and straw. The historical core of Yemen covers about $20,000 \mathrm{~m}^{2}$ and is accessible only through one gateway [4].

The primary innovator concerned with the modernisation of earthen building materials in modern times was the French architect Francois Cointreau (1740-1830). In 1787, he invented a variety of methods that form soil into a solid material, with mechanical and chemical properties that are easier to work with; he collaborated in this with such architects as Claude Ledoux and E.-L. Boullée. Books published in
Europe, America and Australia have shown factories, schools, offices, public services and housing that can be built in different designs and for different geographical areas, using related techniques. Since the beginning of the twentieth century, the appearance of various manufactured materials, such as cement, stone, iron, aluminum and sand products, have tended to limit the use of mud and earth. On the other hand, many buildings were built from earth when construction materials were scarce, such as in Germany in the 1920s-30s and East Germany in the 1940s-50s. In the Third World, mud architecture was taking off at the same time. In 1943, a regional hospital in the city of Edrad in Algeria was built by Belgian architect Michel Luyckx. The International Center for Research and Application of Mud in Grenoble has studied and delineated the various traditional construction methods and different types of soil that may be suitable for mud construction. In the United States, mud brick construction began more than four decades ago; modern buildings are being built using this material in California and Mexico, in particular [5].

Architects are responsible for studying, analysing and documenting traditional buildings in order to detect and preserve them. Architects must also contribute to improvements in construction methods and materials, while finding the best ways to exploit and inspire traditional architectural methods that express the culture of the community in housing projects addressing community needs, such as the establishment of affordable housing. Architecture and human factors are brought together in many aspects of mud construction, especially in relation to human comfort and sustainability. 
Sustainability in architecture is a globally acknowledged term; sustainable architecture has become the main concern of many architects around the world. In this instance, mud architecture offers a point of entry linking architecture and housing. It is important to remember in this context the role of Jordan since Paleolithic times, i.e., since the eighth millennium BCE. This territory witnessed the beginnings of human settlement and the development of all types and forms of architecture in terms of their building materials and design. The first houses were built using moulds of mud and mud buildings were created. Traditional mud architecture lies close to human instinct: easy to understand, it stimulates the human senses and meets the needs of human beings while being responsive to their desires. Meanwhile, modern architecture is not flexible and devoid of spirit and originality; there is no difference between modern buildings as constructed in Europe, in America and in the Arabian Gulf region. The product unites construction materials and advanced technology in a practice far removed from human content and the natural environment.

\subsection{Research goals}

The research programme aims to clarify the status of heritage mud architecture in Jordan and to engage the artistic and aesthetic aspects of mud architecture that can be applied in contemporary societies, especially rural ones. The need for such attention is increased today because of the economic requirements to provide alternatives to expensive concrete building methods.

\subsection{Research methodology}

The study was based on methods of description and analysis. The research relied first on two sources of information: information derived from the references and existing works of heritage architecture, especially mud architecture, the second source of information included field surveys as well as laboratory testing.

\subsection{Research hypothesis}

Jordan is one of the countries most able to use mud architecture in its construction practice, because of its urban heritage rich with mud architecture and the nature of its soil, suitable for mud construction. This study asserts that mud architecture may be a successful solution to construct affordable housing, especially as current forms of housing remain expensive.

\section{MUD BUILDINGS IN JORDAN}

\subsection{Mud in popular consciousness}

Mud architecture emphasizes an intimate relationship between human beings and construction and can connect building practices, architectural massing, house shapes, roofing patterns and the surrounding environment. Mud construction realized the desires of traditional architects in architectural forms; as a raw material available in the local environment, it is significant in terms of its physical, structural, emotional, symbolic and cultural aspects. Mud retains popular symbolic value as the initial material from which human beings have created enduring structures. As a product of soil and water, mud combines the principles of receiving and formation. Water is the source of life and the complement of creation. Mud represents a primary material that human beings used to build shelters in villages, after they roamed the desert with their tents.

\subsection{Historical roots of mud architecture in Jordan}

The search for the earliest origins of mud dwellings in a particular area of Jordan remains difficult because of the rapid deterioration of raw materials, but permanent mud dwellings appeared in their earliest forms in the historical period of AlNattouf (8th millennium BCE). This is documented in a number of sites in the Jordan valley, such as Areeha, Tel Abu Hamed, Tel Rama, Ein Al Ghazal, Qaryat Al Hamam, Ras Naqab and other locations. Through archaeological and anthropological perspectives, it is possible to know that early humans lived in caves before moving out onto the land.

Architecture is one of the most important features of material culture, and housing is an indicator of the way of life and the degree of urbanisation of society, representing cultural ideas about stability and attachment to place. Therefore, spaces for living and work have been reconfigured through different eras and cultural practices embodied in differing forms of dwellings and architectural monuments.

Architecture has always been a direct product of human effort and simultaneously an expression of the natural environment. This environment was the main source of materials used for construction in the Jordan Valley, but simple architecture was common and round houses formed a sign of this early construction effort. The circular hut built of mud, stone and wood represented the alphabet with which the history of the architecture was written; it was a common feature of many other buildings in ancient residential communities in the Near East [6].

The techniques and methods of mud construction in Jordan and its neighboring countries, such as Syria and Palestine, where have evolved from one historical period to another. For example, the method of roofing by mud cone domes spread from the villages around Aleppo and elsewhere in northern Syria, as mentioned by geographer Yaqut Alhamawi in his book (Mu'jam Al-Buldan) [7] These patterns were also seen in the villages of the Jordan valley in the northern Shouneh area, Deir Ola, Ghor Al-Safi and in some palm areas such as Jurf Al-Darwish and Al-Jafr. These patterns were also seen in the villages of the Jordan valley in the northern Shouneh area, Deir Ola, Ghor Al-Safi and some palm areas including the AlDarwish and Al-Jafr shelf. Mud and stone houses were implemented in the city of Al-Safawi for several activities and uses, including residential buildings and structures attached to buildings for such purposes as barns, garages and storage places. The internal dimensions of this type of housing ranged between 360 and $440 \mathrm{~cm}$ on each side with a height of not less than $350 \mathrm{~cm}$, with a thickness of not less than $20 \mathrm{~cm}$ in the case of mud brick walls and not less than $50 \mathrm{~cm}$ in the case of basalt stone walls [8].

However, mud bricks have been identified as not representing an engineering material and not for use in government projects, noting that mud bricks need maintenance and repetitive repairs. The only science that can offer an adequate judgment about the strength and reliability of mud is the study of soil mechanics; many experiments have been carried out on using mud as a building material, especially at the University of California, the University of Texas and the 
University of Cairo. Mustafa Yahya, a professor of materials science, looked at several samples of mud bricks and found that the crushing load reached 30 kilograms per square centimeter and that the mud bricks can carry loads under heavy rain conditions. The mud shrinks until it becomes dry, which may take a year or more depending on the degree of permeability of the soil and climatic conditions [9], there is some mud which has proved to be unsatisfactory as building material and over many centuries local people have learned to avoid this particular unsuitable mud. Organic Soils: are mainly useless for wall building. A reliable rule is that if a soil as good for growing plants in, it is not good for building walls with. Mixtures: Find out which soils are contained in the mixture and then the usability depends on the proportion of the various types of soil listed above. Always look at the old buildings in your district and see for yourself the types of soil that have been used, durability, or shortcomings of these old buildings [10].

\section{MUD BRICKS ARE THE PRIMARY BUILDING MATERIAL}

Scientific references concerning mud architecture show that to make mud bricks the greatest percentage of soil must be sand with some clay.

According to the following map of Jordan which shown in Figure 1 based on the distribution of soil, it can be seen that the largest percentage of land in Jordan is sand. Sandy specimens were selected from the east of Jordan and were mixed with water and straw as in Figure 2; after that they were put in $10 * 10 * 10 \mathrm{~cm}$ moulds as shown in Figure 3. Then they were dried very well under the sun's rays and the speciemens were tested using strength device as shown in Figure 4, and the results of testing corresponded with the norms of mud architecture. This showed that the sandy soil can be effectively used for mud construction.
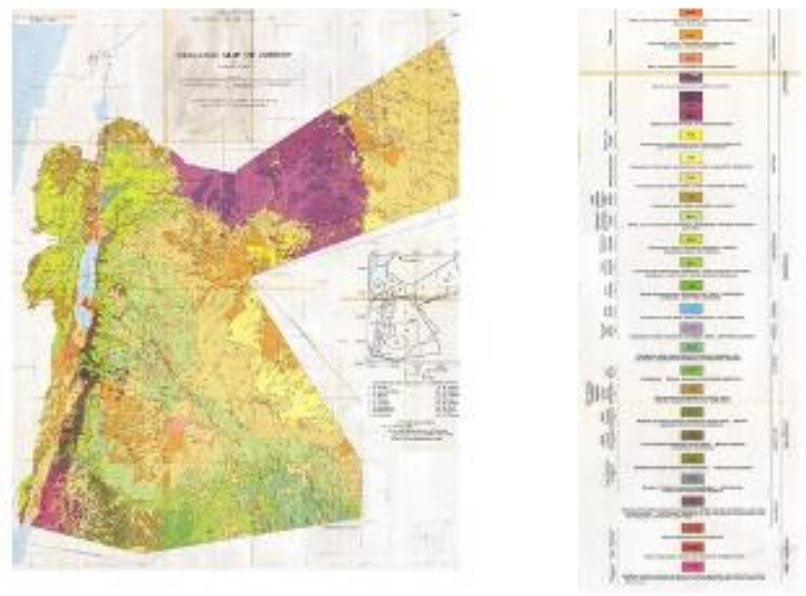

Figure 1. Geological map of Jordan [10]

\begin{tabular}{|l|l|l|}
\hline \multicolumn{2}{|l|}{ Test Name } & Result \\
\hline \multirow{2}{*}{ Specific gravity } & 2.65 \\
\hline \multirow{4}{*}{ Grain Size Analysis } & Gravel $\%$ & $18 \%$ \\
\cline { 3 - 3 } & Sand \% & $55 \%$ \\
\cline { 2 - 3 } & Silt $\%$ & $11 \%$ \\
\cline { 2 - 3 } & Clay\% & $16 \%$ \\
\hline
\end{tabular}

Figure 2. Classification of soil sample

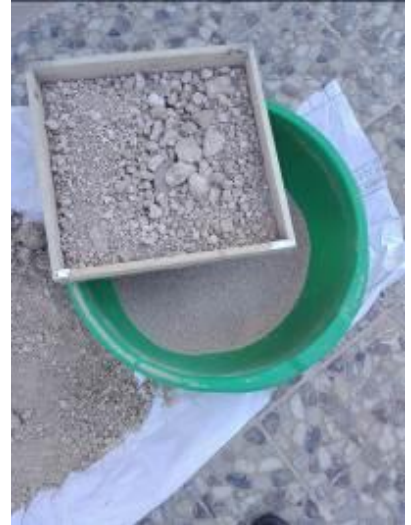

(A) Sand of type was brought from east of Jordan and was sieved with a sieve No. 1

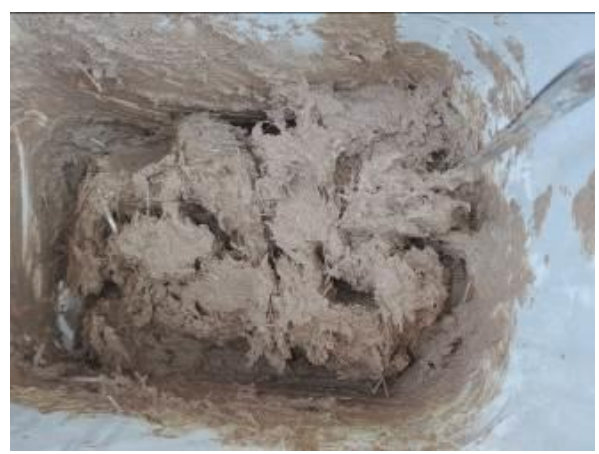

(B) The straw was mixed with soil and water was added as needed

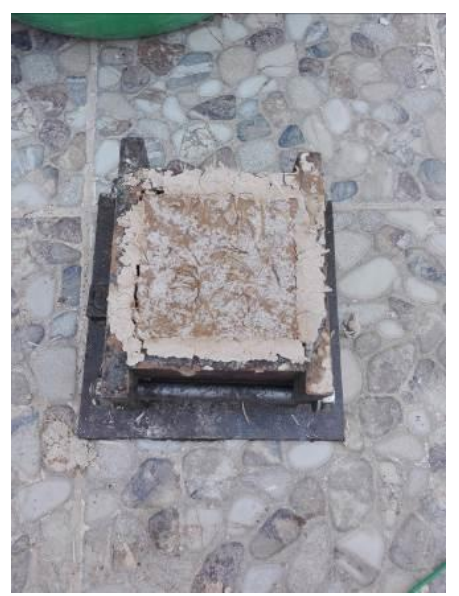

(C) The remains of wheat stalks after milling and this is called hay strew

Figure 3. The main contents of mud brick

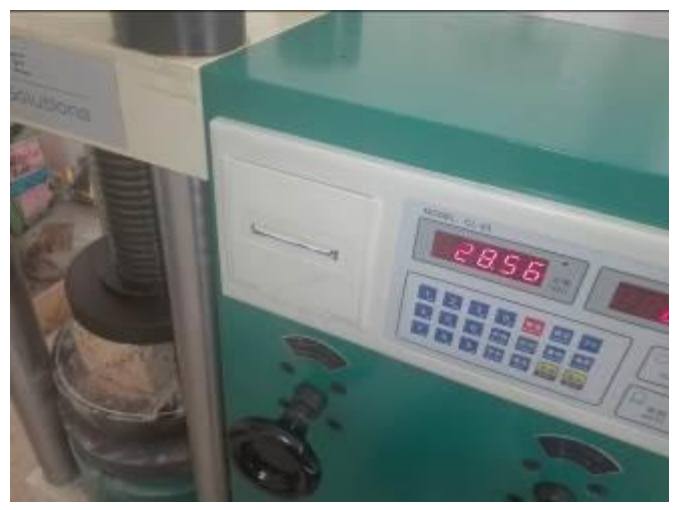

Figure 4. The strength of bricks is $28.56 \mathrm{Kn} / \mathrm{m}^{2}$ 


\section{THE MOST IMPORTANT TYPES OF MUD ARCHITECTURE IN JORDAN}

In the type of roofing most commonly used in mud houses in Jordan, the ceiling consists of a row of tree branches or wood supported by a thick tree trunk and then topped by a net of reeds. Above this, a layer of mud and straw is placed and the entire roof rests on the side walls of the building as shoen in Figure 5.

One of the most famous forms of mud houses in the villages of Jordan was the mud house with a circular domed roof, a mud dome that kept some parts of the surface in shadow as shown in Figure 6. These domes were also used as a thermal chimney, to collect hot air at the top of the conical vessel and spout it out through a hole. Thick, solid outer walls achieve the maximum time delay in thermal conductivity, with mud walls $40 \mathrm{~cm}$ thick delaying the heat by 15 hours. On the other hand, cement block walls with a thickness of $20 \mathrm{~cm}$ delay the heat by only five hours and six minutes.

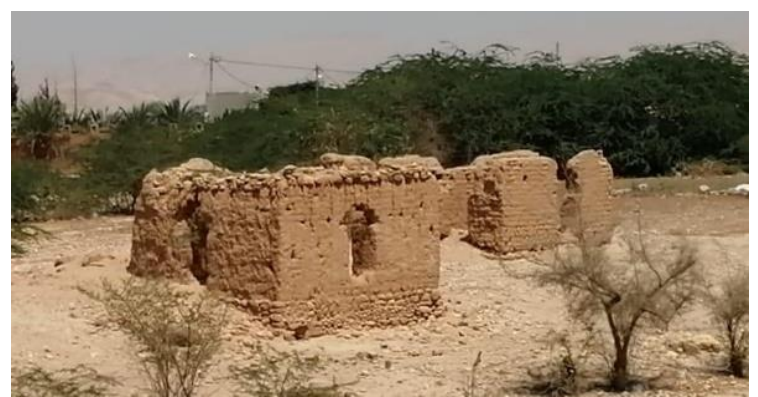

(A) Mud House Model - Southern Jordan Dead Sea Region

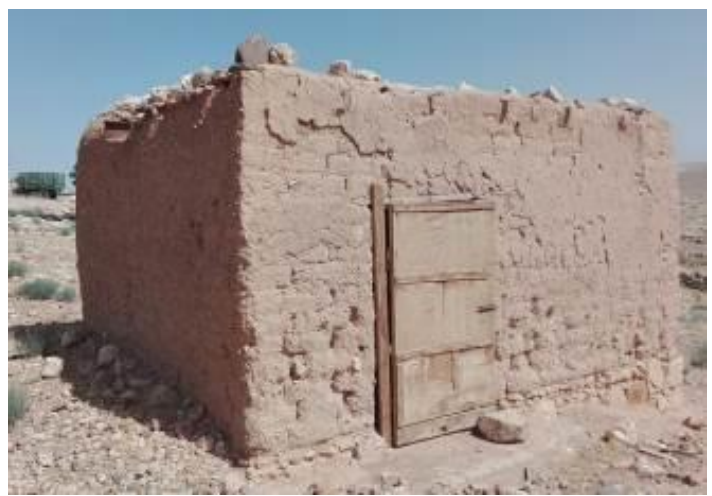

(B) Mud House Model from EasternJordan - Mafraq

Figure 5. A mud house with a flat

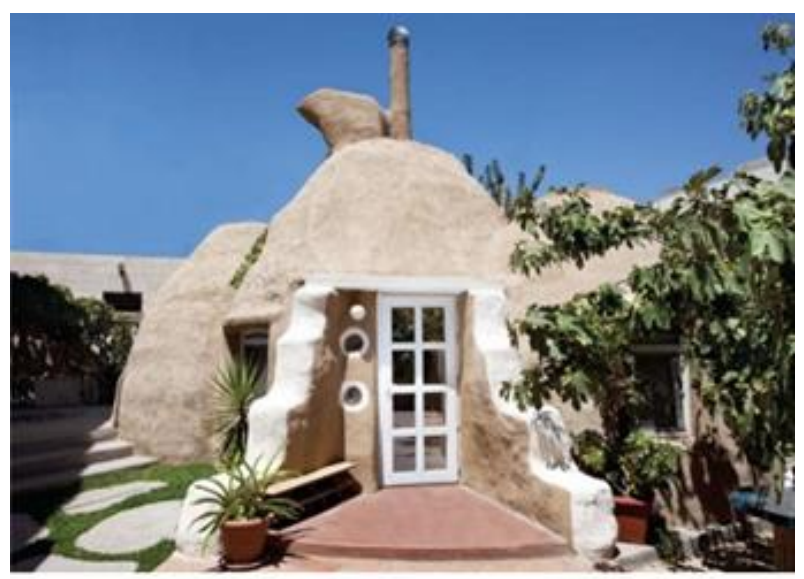

(A) This image illustrates an example of a unique heritage design 'of in Amman [11]

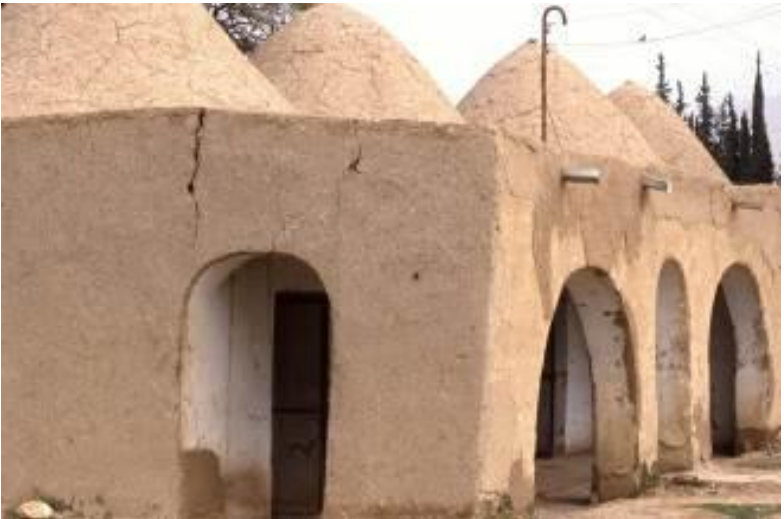

(B) This image illustrates an example of a unique heritage design featuring a vaulted-roofed building with a portico, in the Jordan valley2 [12]

Figure 6. Pictures of mud buildings in Jordan

Unlike a flat roof, a domed ceiling is not completely exposed to sunlight, creating air movement between shaded and sunny sections. This eliminates the layer of hot air associated with continuous sun. In addition, mud stores heat, cold, and humidity. The addition of a binder material contributes the required durability and insulation to the construction [13]. where the main points that affect the local climate of buildings are: the external air temperature and relative humidity, incidental solar radiation, wind speed and direction, air exchange, properties of the building envelope materials [14].

According to Minke [4], mud is effective in absorbing moisture; when humidity is low (less than 50\%), it helps keep the structure intact. People living in mud houses are less susceptible to flue and other contagious diseases, and the advantages of mud construction are most pronounced in the bathroom. When a shower is used, indoor air humidity rises to $90 \%$ in normal bathrooms: if the bathroom is not ventilated, the mirrors are covered with a mist for three quarters of an hour. In mud houses, by contrast, mirrors become clear again after three or four minutes, as the humidity in the air drops to $70 \%$. 'Efficiency of using adobe bricks to construct a housing system deploying any of the four proposed prototypes particularly in rural areas suffering from poverty. This conclusion is based on the following facts: availability and suitability of raw material at low or no cost, production of adobe bricks could be carried out by the end-user with some or without any help from the experts in the field of bricks' production, sun-dried and burnt adobe bricks show an acceptable range of strength, more efficient land use, utilizing a larger percentage ratio of built-up area to land area and acceptable energy efficiency upon using adobe bricks' [15].

An efficient energy economy starts with clay houses right from the choice of materials, because the preparation of mud used in construction consumes only $1 \%$ of the energy consumed by the manufacture of cement bricks or concrete blocks. Moreover, it has been proven in a laboratory setting that mud resists high-frequency electromagnetic waves and absorbs some of them. A mud wall $24 \mathrm{~cm}$ thick protects against high frequency electromagnetic waves better than walls of other materials, several times thicker. that a mud house can be built to resist $99.9 \%$ of high-frequency electromagnetic waves [4].

Porous materials have the capacity absorb humidity from the ambient air and also to release humidity gradually into the 
air, thereby balancing indoor humidity changes. The equilibrium moisture content depends on the temperature and humidity of the ambient air. "The effectiveness of this balancing process also depends upon the absorption or desorption. Experiments conducted at the BRL, for instance, show that the first $1.5-\mathrm{cm}$-thick layer of a mud brick wall is able to absorb about $300 \mathrm{~g}$ of water per $\mathrm{m}^{2}$ of wall surface in 48 hours if the humidity of the ambient air is suddenly raised from $50 \%$ to $80 \%$ ' [4].

\section{HOUSING POLICIES IN JORDAN}

Natural population growth, in addition to demands resulting from forced migration from neighbouring countries, internal migration to the main cities, and related dynamics, are reflected in the process of sustainable development in Jordan. Economic, social and environmental elements factor in the need to develop housing policies and implementation strategies to provide adequate housing, to accommodate the growing population and to ensure a quality life for all segments of society.

The beginning of direct government intervention in housing policy in Jordan was in 1966, when the Housing Establishment was set up to provide affordable housing. In 1973, the Housing Bank was created to provide housing loans at lower financing costs than commercial banks.

In 1980, the government established the Department of Urban Development to implement urban development projects and provide poorly-serviced areas with infrastructure services, as well as superstructure and social structure. To guide the housing sector and address the imbalances resulting from urbanisation and from the lack of coordination among the bodies involved in the implementation of housing projects, the government approved the National Housing Strategy in 1989. This strategy aimed to provide adequate affordable housing, improve the efficiency of the market for real estate, and adopt a targeted private sector alternative while developing housing investment programmes.

To face the challenges of overpopulation and the need for adequate housing, the government committed itself to implementing the recommendations of the National Housing Strategy. In 1992, it unified Jordan's national housing effort, merging the Housing Corporation and the Department of Urban Development into the General Organization for Housing and Urban Development. This has become their legal and practical successor organisation and the main umbrella for the housing and urban development sector.

In 1996, in line with the recommendations of the National Housing Strategy and the government's priority to promote sustainable growth, implementation of the Housing Sector Restructuring Project was approved within the framework of the government's urban sector reform programme. The most important of these initiatives was Abu Nusair in the capital, Amman; this was an extension of previous urban growth towards the Jubaiha area near the site. This project was implemented on a land area of 3,005 acres to produce 6,114 housing units distributed among 16 models ranging from 90 to $140 \mathrm{~m}^{2}$. The project was implemented in several stages and included the provision of serviced plots to allow the beneficiary to build and expand within their physical possibilities as shown in Figure 7. Another important project is the suburb of Princess Iman, east of Amman, which represents a natural extension of the city of Sahab to the south- west. The total area of the project is 880 acres, producing 1,473 serviced residential plots and 69 commercial plots as well as public services. Housing projects have continued to meet the needs of the population and the increasing demand for housing in Jordan, while promoting social cohesion, ensuring economic, social and environmental safety and stabilizing the population in its current location [16].

"Affordable housing is a term used to describe dwelling units the total housing costs of which are deemed "affordable" to a group of people within a specific income range' [17].

Government officials said that prices paid by citizens were reduced by $15 \%$ compared to previous market prices, while the treasury incurred the cost 32 million dinars and lands were also distributed. Unfortunately, this initiative did not meet with success for several reasons, the most important of which were the high cost of affordable housing, despite government support, and the lack of satisfactory implementation. The results produced by contractors were unsatisfactory for the users of the units constructed in terms of quality, especially when compared to regular units offered on the local market. Complaints concerning the poor design of the apartments faced the Abu Alanda project, one of Karim housing projects in Amman. People occupying the units were surprised by their structural weaknesses evident in walls that threatened collapse when penetrated by humidity. These apartments were not free of charge, either; an apartment with an area of $135 \mathrm{~m}^{2}$ cost approximately 32972 dinars, and the cumulative monthly bank payments total twice that amount.

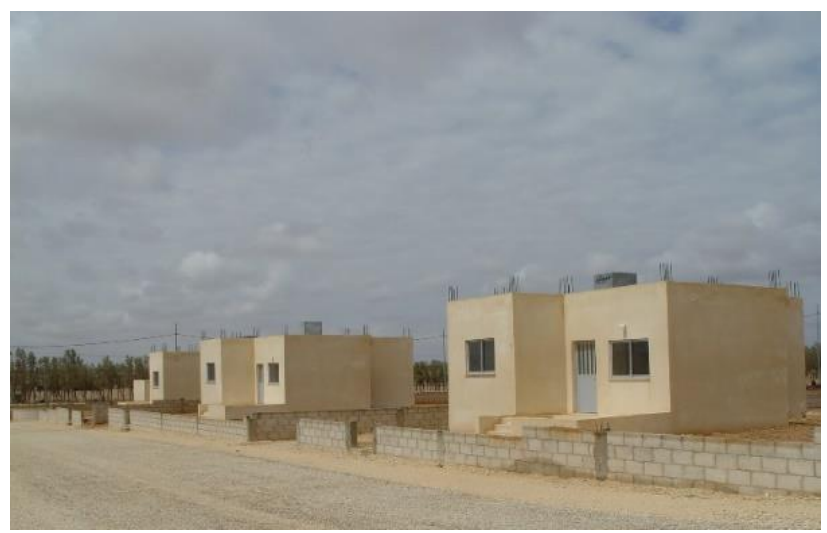

(A) Distribution of prefabricated buildings to affordable housing users

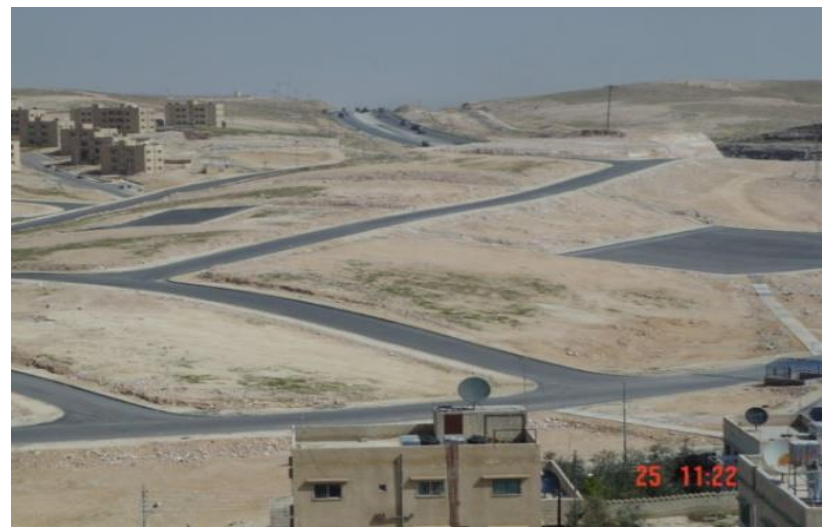

(B) Distribution of land to affordable housing users

Figure 7. Housing projects of the Housing and Urban Development Corporation 


\section{HOUSING POLICIES AND THEIR RELATIONSHIP TO THE PRINCIPLES OF SUSTAINABLE DEVELOPMENT}

The Jordanian government seeks in its housing policy to provide housing for people with limited income without linking these policies to local materials with a low cost, such as clay, and thus reducing the cost for limited income, so that this housing becomes cheap for them, the construction of mud would have been a mutual activity, involving the members of one or more family, implying the existence of social units consisting of cooperating persons which reduce the cost of construction [18].

Sustainable development, in its overall sense, is linked to improving the quality of life for all segments of present-day society without affecting the ability of subsequent generations to meet their own future needs. To achieve sustainable human development requires a focus on the social, environmental and economic dimensions of human development. 'However, factors that affect housing demand in Jordan in general, and low-income housing demand in specific are: demographics and the total population that resides in three major cities, namely Amman, Irbid and Zarqa' [19].

In housing policy, where housing is a basic human need and one of the main factors in improving the quality of life, the main challenge in Jordanian housing policy is to meet housing needs and to adapt to the growth rates of the population by providing healthy housing at prices commensurate with citizens' requirements. Greater equality of opportunity and combating urban poverty, while balancing the distribution of the population and of housing, are key development requirements. To meet this challenge, housing policies and housing production must be aligned with the requirements of economic, social and environmental growth in light of the high costs of housing production, especially since the price of the housing unit is eight times the annual income of the family.

'One of the main challenges facing Jordan in respect to housing policy is determining best practices for dealing with the escalating demand for housing that has arisen as a result not only of high population growth (2.4\% per annum) of its own citizens, but also following influxes of forced migrations from the surrounding countries including Palestinian, Syrian and Iraqi refugees. The housing sector has witnessed an enormous increase, with the number of housing units increasing from 376,822 units in 1979 to 835,604 units 1994 , and approximately 1.2 million units in 2010. Low-income households constitute about $45 \%$ of total households in Jordan' [20].

According to this 2016 study, the factors leading to Jordan's housing problems were:

(1): High population growth, rural to urban migration and adverse external migration. The low income of the citizen and the continuous rise in land prices.

(2): Lack of a general housing policy that takes into account priorities, population distribution and housing needs.

(3): Population increase: the growth rate of the total population during the period 2004-2015 is about 5.3\% [21].

(4): Lack of national economic resources, shown through budget deficits.

(5): Unemployment and low income for individuals.

(6): Continuously increasing housing prices due to increases in the prices of imported building materials.

(7): Increased demand for housing as a result of social development and tendency for young people to form nuclear families apart from their extended families. Housing costs thus represent $28.8 \%$ of Jordan's Cost of Living Index, which reflects the importance of housing spending for the population in general.

\section{CONCLUSIONS}

This study concludes:

(1): The use of available local materials contributes to achieving the concept of sustainable development by preserving the environmental, economic and social dimensions of buildings and achieving community participation.

(2): Mud is one of the most environmentally sound materials as it does not release any form of pollution during its manufacture, use or repair or in the case of demolition or renovation of the building. It comes from the ground and returns to it.

(3): Mud is available in most areas of Jordan, which makes the local people self-reliant in producing and using this material.

(4): Mud stores heat, cold and humidity and thus improves the indoor climate; by adding certain bonding materials it can achieve the required durability and insulation features required in many constructions uses.

(5): Mud economises the energy used in its manufacturing, because mud needs only $1 \%$ of the energy required for concrete production.

(6): Thick external walls made of solid mud achieve the maximum time delay in thermal conductivity; the walls of mud with a thickness of $40 \mathrm{~cm}$ delay heat transfer by 15 hours, while cement block walls $20 \mathrm{~cm}$ thick only retain the heat for five hours and six minutes.

(7): Comparing a mud building with a concrete building, economic savings of $35 \%$ were achieved compared to the concrete building, as repeated in several previous studies.

(8): This cheap material available can allow direct and rapid production and construction, which helps to provide housing for people with limited income at the lowest possible cost.

(9): The geography of Jordan permits the construction of mud houses by providing soil suitable for mud construction in most regions.

(10): The adoption of mud architecture restores the intimate relationship between human beings and architecture as represented in the sizes and forms, and the design and heritage elements stemming from its human scale.

\section{RECOMMENDATIONS}

(1): To return to the technique of mud construction and to reuse this highly sustainable material.

(2): To follow up the implementation of construction projects for the poor by using low-cost mud buildings to meet the need for affordable housing.

(3): To give simple loans for citizens to build their houses using mud construction.

(4): To communicate with international institutions, funding agencies, investors and the private sector, to ensure support for this eco-economic housing model.

(5): To raise awareness of mud-building technologies in buildings, especially in suitable areas such as the Jordan valley and Wadi Musa, and to attract tourists from all over the world 
to see both heritage and modern mud housing.

(6): To restore and make use of existing locally-produced mud houses.

(7): To provide field training opportunities in order to provide skilled labour that can construct mud buildings for traditional and modern requirements by traditional methods.

(8): Where mud construction faces challenges in certain applications, such as strength limitations, to consider hybrids between concrete and mud brick architecture.

(9): For architects to develop more modern models of mud architecture in Jordan, taking into account techniques that have proved their durability and strength through heritage houses located in many parts of the country.

\section{ACKNOWLEDGMENT}

This work has been carried out during sabbatical leave granted to the author Mohannad Tarrad from Al Al-Bayt University during the academic year 2018-2019.

\section{REFERENCES}

[1] Sruthi, G.S. (2013). Mud Architecture. International Journal of Innovative Research in Science, Engineering and Technology, 2(1): 47-49.

[2] http://www.unesco.org/new/ar/unesco/resources/earthen -architecture-the-environmentally-friendly-buildingblocks-of-tangible-and-intangible-heritage/, accessed on December 17, 2019.

[3] Usama, K., Waled, F., Reid, A. (2016). The Use of Mud Material in Desert Cities' Construction as an approach to Sustainability: Ghadames as a Case Study, Tanta University Third International Environmental Forum.

[4] Gernot, M. (2006). Building with Earth, Design and Technology of a Sustainable Architecture, publishers for Architecture, Basel, Berlin, Boston.

[5] Isam, S.S., Yser, K.A. (2017). Clay architecture from a contemporary vision (future vision). Journal of Engineering Sciences, 45(5): 712-714.

[6] Ali, A. (2002). Mud Villages (gra al-ten), Historical Engineering Study, Arabic language book, Ministry of Culture Publications, Syrian Arab Republic, p. 41. (in Arabic).

[7] Yaqut, A. (1970). Mu'jam Al-Buldan, Beirut, Wikiwand, p1/261-265. (in Arabic).

[8] Yahia, Y.A., Suad, A., Hasan, A. (2001). The Influence of Desert Area on Architectural Design- The available and Building Materials in Jordan Desert. Conference,
KSA, pp. 10-11. (in Arabic).

[9] Hassan, F. (1989). Architecture for the poor: An experiment in rural Egypt. Cairo: American University in Cairo Press, pp. 255-260.

[10] Fridrich, B. (1975). Geology of the Arabian Peninsula Jordan, Geological Survey proffesional paper 560-I, prepared in cooperation with the government of Jordan and the geological survey of the Fedral Republic of Germany.

[11] Marwa, F. (2012). Mud houses are eco-friendly houses(Bouot al-ten). Bonah Magazine, Al-amara walbenaa (in Arabic). http://www.bonah.org/\%d8\%a8\%d9\%8a\%d9\%88\%d8 \%aa-, accessed on Jan. 12, 2020.

[12] Ammar, K. (1983). A mud house in south-east of Tel Deir Alla, Central Jordan Valley, Jordan. https://www.facebook.com/photo?fbid=9144413152928 71\&set=pb.100001810331745.-2207520000, accessed on Jan. 12, 2020.

[13] Hassan, F. (1986). Natural energy and vernacular architecture principles and examples with references to hot arid climates. United Nations University.

[14] Blanco, I., Schettini, E., Vox, G. (2018). Effects of vertical green technology on building surface temperature. International Journal of Design \& Nature and Ecodynamics, 13(4): 384-394. https://doi.org/10.2495/DNE-V13-N4-384-394

[15] Abu-Hammad, N.O. (2011). Architectural mud brick prototypes as efficient and sustainable shelters for the low-income group in Jordan. Jordan Journal of Civil Engineering, 5(1).

[16] Housing and Urban Development Corporation. (2018). Jordan.

[17] Rinku, T., Vidya, D.T. (2009). Low-cost housing: International Conference on Advances in Concrete Structural and Geotechnical Engineering, BITS Pilani, India.

[18] Barnard, Els. (2016). Living in mud houses: exploring the materiality of Formative Mesoamerican domestic structures. Mexicon, 38: 39-45

[19] Majd, A., Salem, A., Mutasem, A. (2009). The low income housing market in Jordan. International Journal of Housing Markets and Analysis, 2(3): 234. https://doi.org/10.1108/17538270910977536

[20] Jamal, A.A. (2016). Affordability of low income housing in Amman, Jordan. Jordan Journal of Economic Scenes, 13(1): 66

[21] Department of Statistics, Jordan, (2015). http://dosweb.dos.gov.jo/censuses/population_housing/c ensus2015/, accessed on Jan. 12, 2020. 